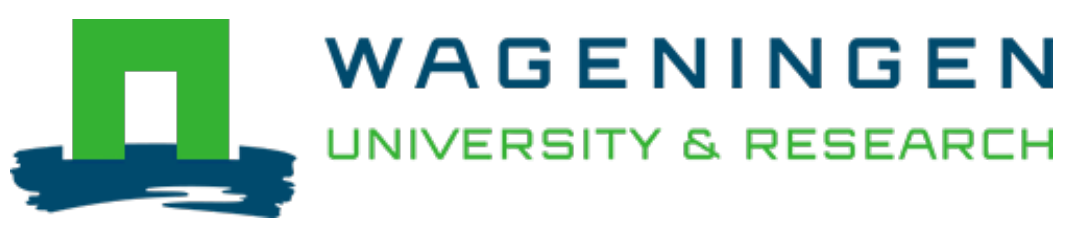

\title{
Institutionalising reflexivity? Transformative learning and the Intergovernmental science-policy Platform on Biodiversity and Ecosystem Services (IPBES)
}

\author{
Environmental Science \& Policy \\ Borie, Maud; Gustafsson, Karin M.; Obermeister, Noam; Turnhout, Esther; Bridgewater, Peter \\ https://doi.org/10.1016/j.envsci.2020.05.005
}

This article is made publicly available in the institutional repository of Wageningen University and Research, under the terms of article $25 \mathrm{fa}$ of the Dutch Copyright Act, also known as the Amendment Taverne. This has been done with explicit consent by the author.

Article 25 fa states that the author of a short scientific work funded either wholly or partially by Dutch public funds is entitled to make that work publicly available for no consideration following a reasonable period of time after the work was first published, provided that clear reference is made to the source of the first publication of the work.

This publication is distributed under The Association of Universities in the Netherlands (VSNU) 'Article $25 \mathrm{fa}$ implementation' project. In this project research outputs of researchers employed by Dutch Universities that comply with the legal requirements of Article $25 \mathrm{fa}$ of the Dutch Copyright Act are distributed online and free of cost or other barriers in institutional repositories. Research outputs are distributed six months after their first online publication in the original published version and with proper attribution to the source of the original publication.

You are permitted to download and use the publication for personal purposes. All rights remain with the author(s) and / or copyright owner(s) of this work. Any use of the publication or parts of it other than authorised under article $25 \mathrm{fa}$ of the Dutch Copyright act is prohibited. Wageningen University \& Research and the author(s) of this publication shall not be held responsible or liable for any damages resulting from your (re)use of this publication.

For questions regarding the public availability of this article please contact openscience.library@,wur.nl 


\title{
Institutionalising reflexivity? Transformative learning and the Intergovernmental science-policy Platform on Biodiversity and Ecosystem Services (IPBES)
}

\author{
Maud Borie $^{\mathrm{a}, *}$, Karin M. Gustafsson ${ }^{\mathrm{b}}$, Noam Obermeister ${ }^{\mathrm{c}}$, Esther Turnhout ${ }^{\mathrm{d}}$, Peter Bridgewater, ${ }^{\mathrm{e}, \mathrm{f}}$ \\ ${ }^{a}$ Department of Geography, King's College London, London, UK \\ b Environmental Sociology Section, Örebro University, Örebro, Sweden \\ ${ }^{\mathrm{c}}$ Department of Geography, University of Cambridge, Cambridge, UK \\ ${ }^{\mathrm{d}}$ Department of Environmental Sciences, Wageningen University, Wageningen, the Netherlands \\ ${ }^{\mathrm{e}}$ Institute for Applied Ecology and Institute for Governance and Policy Analysis, University of Canberra, Canberra, Australia \\ ${ }^{\mathrm{f}}$ Centre for Museums and Heritage, Australian National University, Canberra, Australia
}

\section{A R T I C L E I N F O}

\section{Keywords:}

Transformation

Reflexivity

Learning

IPBES

Science-policy interface

\begin{abstract}
A B S T R A C T
In the wake of controversies surrounding both the legitimacy and effectiveness of intergovernmental expert organisations, the Intergovernmental Science-Policy Platform on Biodiversity and Ecosystem Services (IPBES) was established in 2012 as a new intergovernmental expert organisation with the explicit mandate to move beyond 'one-size-fits-it-all' approaches. During its first eight years of operating, this attempt to 'do different' has made IPBES develop into a space for individual, experiential, and organisational learning and has made significant progress towards becoming a 'learning organisation'. However, learning can take different forms. Looking towards the future development of IPBES, the importance of transformative learning and the need to establish institutional reflexive processes in which this transformative learning can take place will be critical. IPBES has a number of novel features, three key features facilitating transformative learning are its ambitious principles and inclusive approach to a wide range expertise and knowledges, its fellowship programme, and commitment to a transparent and on-going review process. While IPBES' social organisation is significantly different from previous initiatives and has created opportunities for transformative learning, not all learning and all changes that have taken place have been reflexive and some innovative features also have had unintended consequences for the results of the learning activities. As a result, to live up to its ambitions of contributing to positive and transformative societal and environmental change, IPBES must strengthen its capacity for transformative learning. Some proposals on how to systemise it further are outlined.
\end{abstract}

\section{Introduction: IPBES and transformative learning}

In the wake of the Climategate controversy (2010) which placed the credibility of climate scientists involved in the Intergovernmental Panel on Climate Change (IPCC) centre stage, discussions on the best way to organize environmental expert advice in a global context unfolded in policy, practitioner and academic worlds (e.g. Beck et al., 2014; Pallett and Chilvers, 2015). These fed into, and coincided with, the birth of the Intergovernmental science-policy Platform on Biodiversity and
Ecosystem Services (IPBES) in 2012. Although it has often been described as an 'IPCC for biodiversity', from its inception IPBES has drawn lessons from the IPCC, and other expert organisations, but has also attempted to 'do different'. The mandate of IPBES claims it will 'strengthen the science-policy interface for biodiversity and ecosystem services for the conservation and sustainable use of biodiversity, longterm human well-being and sustainable development ${ }^{1}$. While much has been written on IPBES ${ }^{2}$, this contribution is focused on learning and global expert organisations - arguing for its importance and asking in

\footnotetext{
${ }^{*}$ Corresponding author.

E-mail addresses: maud.borie@kcl.ac.uk (M. Borie), Karin.M.Gustafsson@oru.se (K.M. Gustafsson), no291@cam.ac.uk (N. Obermeister), esther.turnhout@wur.nl (E. Turnhout), Peter.Bridgewater@canberra.edu.au (P. Bridgewater).

${ }^{1}$ https://ipbes.net/about, last accessed March, $3^{\text {rd }}, 2020$.

${ }^{2}$ According to a keyword search conducted on Scopus in March 2020 at least 89 papers have been published on IPBES since 2011 with a maximum of 21 papers in 2018 so far (search: 'IPBES' in title), this number increases to 237 if we also include abstracts and keywords in the search.
} 
particular whether transformative learning and reflexivity can be institutionalised.

At the seventh session of its Plenary (IPBES-7), Paris April 9-May 4 2019, delegates from over 130 member states accepted IPBES' first global assessment and approved its Summary for Policymakers. The IPBES Global Assessment Report on Biodiversity and Ecosystem Services is the culmination of several years of work and was widely reported in the scientific and general media, contributing to IPBES' improved public visibility. This media attention was an increase in comparison with previous reportage of the first two thematic assessments, on pollination and pollinators (2016) and on land degradation (2018), and the four regional assessments released in 2018. If the approval of the Summary for Policymakers of the Global Assessment was the highlight of IPBES-7, Decision 7-2 on the review of the platform and Decision 7-1 on the adoption of a new, flexible Work Programme up to 2030 were also important milestones at IPBES-7 in the Platform's development.

Eight years on from its creation, this is a timely opportunity to revisit IPBES' objectives while looking forward to new developments. Reviewing these objectives is also important not only for IPBES but also in the context of the negotiations towards a post-2020 Global Biodiversity Framework (e.g. Visconti et al., 2019). As researchers, observers, or participants in IPBES, we take Turnhout et al's (2012) rules of engagement for the IPBES, and more particularly rule 9 ('reflect regularly to identify areas of improvement'), as an invitation to draw our attention to the diverse forms of learning taking place within IPBES and reflect on achievements and challenges, to date. We believe that IPBES has made significant progress towards becoming a 'learning organisation', but more remains to be accomplished. In light of our analysis, we suggest that IPBES needs to strengthen its capacity for transformative learning and we identify opportunities to do so.

Although the concept of transformative learning has a complex theoretical background (Taylor and Cranton, 2012), and has had its fair share of transformations since it was originally posited by Jack Mezirow (1978, see also 1997), it has become ubiquitous in discussions around sustainability (e.g. Westley et al., 2011; O’Brien, 2012; König, 2015). Here, we use it not only as a shorthand for 'learning that creates changes', i.e. learning that leads to substantial and long-lasting transformations, but also learning that is achieved reflexively:

'The concept of reflexivity implies going beyond reflection; which would emphasize the breadth of inputs to a learning process, and attend to the openness of outputs, representing a concern to embrace multiple perspectives and knowledges.' (Pallett and Chilvers, 2013:1164, after Smith and Stirling, 2007)

Argyris and Schön (1997) usefully differentiate between single loop and double loop learning (i.e. achieving an objective better versus questioning the objective itself), a distinction which resonates with instrumental and transformative learning, respectively (Pallett and Chilvers, 2013). However, transformations are not inherently positive and different forms of learning, possibly complementary or interdependent, exist (Kolb, 2014; Kolb and Kolb, 2005; Reber, 1989). In efforts to foster and take stock of this, what matters is that decisions, to transform or to uphold something, are made reflexively (Voss et al., 2006; Smith et al., 2005). Indeed, in each situation there is the possibility to go either way. In light of the numerous discussions on transformations and sustainability transitions that are taking place in academia (for a comprehensive review see Scoones et al., 2020), and in other spheres, we use the concept of transformative learning to connect to the broad range of literature published on transformations while underlining the key role of reflexivity.

The need for learning has been acknowledged early on and in different ways within IPBES itself. It is reflected in particular in the IPBES principles and rules of engagement (IPBES, 2012; Diaz-Reviriego, 2019). For example, at the meeting which established IPBES (Busan, 2010 ) it was agreed that IPBES should strive to achieve a balance between experts from different United Nations regions, to encompass diverse forms of expertise and knowledge systems while being genderbalanced and developing an even-handed portfolio of capacity-building activities. The need for learning is also inscribed in the future work programme which includes a review of the IPBES conceptual framework (Díaz et al., 2015). These aspirations echo a number of academic calls and resonate strongly with the ideas of inclusivity and reflexivity (Dryzek and Pickering, 2017; Beck et al., 2014; Turnhout et al., 2012). The former points towards the imperative to reach out broadly ('have more inputs'), whereas the latter is more about the imperative to be aware of why and how particular views are included and not others.

\section{Spaces of learning in IPBES}

As both a social network and intergovernmental institution, IPBES constitutes a space for individual, experiential, and organisational learning. In what follows, we discuss three learning spaces within IPBES and reflect on their interactions with transformative learning. The first section demonstrates connections between experiential and organisational learning; the second reflects on how early- to mid-career researchers learn to become experts in these settings (focusing on the IPBES fellowship programme); and the third section details an explicitly transformative process by which IPBES itself should be learning: the review requested by the Plenary. This request and subsequent review can be interpreted by the organisation sensu lato as reflecting the willingness to learn from previous initiatives. We use these three examples as a way to illustrate our argument but there is, of course, a broader range of learning processes taking place in IPBES such as efforts to close gaps in expertise and the efforts to include indigenous and local knowledge (ILK) spearheaded by the ILK Task Force, ${ }^{3}$ stakeholders (e.g. IIFBES), ${ }^{4}$ and the academic community (e.g. Tengö et al., 2017). Crucially, however, transformative learning is not easy to monitor: while some spaces of learning are formally delineated, learning also takes place in 'shadow spaces' that are more implicit and informal (e.g. Pelling et al., 2008; Pallett, 2018). We further discuss this tension between formal and informal spaces and how they contribute to transformative learning in section 3 .

\subsection{Global assessment and negotiation processes: learning from experience}

Through its various assessment reports, IPBES seeks to promote transformative change by informing society about the drivers, impacts, and solutions to the degradation and loss of biodiversity and ecosystem services. This transformative change is, in its own words: 'a fundamental, system-wide reorganisation across technological, economic and social factors, including paradigms, goals and values' (IPBES, 2019a:5). While achieving this objective is not the sole responsibility of IPBES, and the view from IPBES is one amongst multiple others (see Scoones et al., 2015; Jasanoff, 2007), it does imply that IPBES tries to reach a broad audience and deliver social and political impacts globally. To this end, it is necessary to draw on lessons from previous assessment initiatives and the ways in which they have been able to achieve credibility, relevance, salience, and legitimacy (e.g. Heink et al., 2015).

There are some clear connections between IPBES and other expert organisations. For example, 'multi-sited' experts having participated in other assessments such as the Intergovernmental Panel on Climate Change (IPCC) or the Millennium Ecosystem Assessment (MA), bring in their experiences on how these other processes function (e.g. Leemans, 2008). For instance, the first two chairs of IPBES had also acted as Chairs of various assessments, including the IPCC and the MA. These experts bring with them knowledge and experiences invaluable to newcomers in learning to operate within the novel space that IPBES was and continues to be, and themselves learn from the novelties that space

\footnotetext{
${ }^{3}$ Established to design approaches and procedures designed to deal with ILK.

${ }^{4}$ International Indigenous Forum on Biodiversity and Ecosystem Services.
} 
provides. Interactions between old-hands and newcomers can facilitate learning and help participants navigate the United Nations context, its vocabulary and functioning, as well as develop the skills relevant to a very particular form of science-policy interfacing (the intergovernmental assessment being the most widespread, but not the only one). Indeed, although there are some explicit documents of learning (e.g. the guide on the production of assessments), experiential learning - through observing or taking part in a Plenary or author meeting, for example - is key. The authors learn how to deploy the appropriate vocabulary to express their results ('the evidence shows that...'), the certainty of the claims, or to define important terms (conservation and sustainable use, nature and nature's contributions to people, biocultural diversity, see Bridgewater and Rotherham, 2019; Hughes and Vadrot, 2019). This learning is inscribed in the second work programme which asks the Secretariat to collect more systematically the individual experiences of assessment authors. This highlights potential connections between individual and organisational learning.

Yet, learning from previous initiatives, whether it is individual or organisational learning, is not necessarily transformative. A key example relates to the rules of procedures on which these organisations operate. For IPBES, the IPCC rules of procedures have repeatedly been used as a template and basis for discussion and in developing their own rules of procedures, as well as in developing guidelines for practice in IPBES. These institutionalised rules and practices come to shape the ways in which other experts learn how to do assessments and navigate these settings. Yet these rules and practices probably suffer from being imported rather than revisited and refined. For truly transformative learning, IPBES would have to interrogate the assumptions behind some rules and procedures within the IPCC (and other similar bodies) before either reformulating and assimilating them, or consciously moving away from them (in possibly quite radical ways). Similarly, experiential learning can be superficial or deep (Marton and Säljö, 1976). Arguably, superficial learning happens if the experiences of previous authors are used to accelerate and consolidate the learning of new authors. Deep learning would, for example, involve building on the experiences of authors and other actors (e.g. Secretariat, Technical Support Units) in transforming how current and future assessments are conceived, scoped and effected. However, except for IPBES' fellowship programme, new members of the IPBES network are hardly socialised into the inner workings of the Platform.

\subsection{The IPBES fellowship programme: making experts}

A substantial component of IPBES' capacity-building function is its fellowship programme; one of the organisation's most important formal spaces for individual and institutional learning. The IPBES fellowship programme allows early-career researchers and practitioners to learn from participating in IPBES, primarily the IPBES assessments, as well as by taking part in additional capacity-building activities. The idea of the fellowship programme is to facilitate institutional learning by creating a pole of competent experts who are knowledgeable of IPBES' work process. Two cohorts have so far gone through the programme, and additional fellows are currently participating in IPBES ongoing assessments, as well as in IPBES' work on models and scenarios. The fellowship programme is described by IPBES itself as a success by referring to the fellows' important contribution to the assessments, the establishment of an alumni network, and the fact that some of the graduated fellows already are participating as Lead Authors in another IPBES assessment, and mentoring new recruits to the Fellowship.

Research, studying the fellowship programme from a position outside of IPBES, supports this declaration of success by showing how the fellows have appropriated both the skills of how to do an assessment, and the identity of being an IPBES expert (Gustafsson, 2018). However, this research also shows that the fellowship experience varies greatly between the individual fellows depending on what chapter they are working on, which lead authors they are collaborating with, and what previous competence they are building on. Thus, the content of the institutional learning that is generated by the fellowship programme is not only formed by IPBES itself, but is also to a large extent dependent on the knowledge that fellows and lead authors bring to IPBES' work. This makes the selection of fellows and lead authors - among the nominees - crucial for the content and prospects of IPBES' institutional learning. In this sense, the question of inclusion becomes a precondition for institutional learning and for IPBES' reflexive capacity.

Importantly, in relation to transformative learning, this fellowship programme constitutes a key space for young experts to learn how to gain confidence regarding what constitutes relevant knowledge and sound science that is worthy of inclusion in the deliverables of the Platform. In other words, the fellowship programme offers opportunities for transformative learning insofar as the fellows learn from more experienced IPBES experts how 'policy-relevant' knowledge is created by drawing and overcoming boundaries between science and policy, as well as between different forms of knowledge (Jasanoff, 1987; Gieryn, 1983). While the fellowship programme holds the potential to contribute to transformative change both within and beyond IPBES, recent research shows that this is not the only outcome of the programme. The fellowship programme also contributes to standardise expertise as it 'unintentionally creates restrictions for the boundary work between different knowledge-systems' (Gustafsson et al., 2019:181). This means that although this programme is a key element of IPBES' capacitybuilding and an opportunity for transformative learning, it may also provide an incentive for IPBES to keep doing the same rather than to start doing things differently.

\subsection{The IPBES review: a transformative process?}

The IPCC had been the object of an independent review by the InterAcademy Council in the wake of the Climategate controversy (see IAC, 2010). In the case of IPBES, a review of IPBES' first work programme was commissioned by Plenary- 5 and a report from the review panel was presented during IPBES-7 (IPBES, 2019b). This exercise included an internal component, that focused on reflections from members of the IPBES Bureau and Multidisciplinary Experts Panel, and an external component, supervised by a panel of 10 independent individuals. The Terms of Reference were 'to evaluate the effectiveness of IPBES as a science-policy interface', looking in particular at the implementation of IPBES functions; its internal policies, governance structure; communication and stakeholder engagement strategy as well as funding. The review team had a support team from the International Science Council and conducted its work in a relatively short period of time - with a first meeting in June 2018. The methodology used by the review panel included an online survey; a bibliometric study; a media impact study as well as some focus groups and interviews with national focal points, NGOs and academics involved with or having studied IPBES and other expert organisations. Results were presented in the form of recommendations organised around themes including: (1) origins; conceptualisation and positioning of IPBES; (2) governance, structure and procedures; (3) implementation of the first work programme; (4) budget and financial arrangements; (5) impact (see also Stevance et al., 2020).

Among these, several recommendations emphasised the need for IPBES to strengthen the policy dimension of its work:

'IPBES needs to diversify and be more explicit about the different kinds of expertise needed for different activities, and the criteria applied for expert selection, to strengthen the policy dimension within IPBES.' (2019c:55)

'IPBES should take a more holistic approach to assessment, and must strengthen significantly the policy dimension of its work, with policy relevance at national and local levels framing all aspects of IPBES assessment, which should (i) include practitioners; (ii) develop the capacity to understand how the policy process work; (iii) 
assess the effectiveness of policies; (iv) generate policy choices within the assessment that are more closely policy prescriptive; and (v) develop simple and compelling argument for actionable evidence; tools and options to a range of public and private decisionmakers.' (2019c:73)

This point has been formulated elsewhere, with scholars advocating for 'going beyond assessment' (Hulme et al., 2011) or new ways of doing assessments (e.g. Beck 2011). Instead of reinforcing the other functions ${ }^{5}$ in addition to assessments, IPBES could have made the other functions central and the assessments more peripheral (Bridgewater et al., 2019). Alternatively, IPBES could have chosen to do shorter cycles and shorter documents, and it would have been interesting to have a conversation on the expected length of assessment reports to begin with. Critical though - and as highlighted in these two quotes - is the claim that as a science-policy interface IPBES is still too much science and not enough policy.

IPBES is at the fulcrum of many interfaces across organisations, sectors, scales and disciplines. This poses particular coordination challenges that IPBES must manage and that are better described through the boundary organisation model outlined in the literature on science policy interfacing (Heink et al., 2015; Gustafsson et al., 2019; Obermeister, 2019). In practice, however, the learning relationship needed to translate science to policy is much more fluid. This learning challenge is on-going, and in the case of IPBES complicated by it being a knowledge-policy interface, not simply a science-policy interface. From its inception, IPBES made much of being an inclusive organisation and strives to involve its full range of stakeholders in all its activities. Unsurprisingly this generated many different tensions (e.g. Borie, 2016; Obermeister, 2017; Hughes and Vadrot, 2019) and resulted in a finding in the review that 'IPBES needs to develop a more strategic and collaborative approach to stakeholders' (IPBES, 2019c:9). Given the complexity of the stakeholder links to IPBES, to their stakeholders, and to the wider world only a more structured approach to learning within IPBES would more systematically produce desirable solutions.

Another key area identified, which will impact the learning process, was the lack of a:

'Clearly articulated vision, mission and adaptive strategy cognisant of the multiple (eco)systems in which IPBES operates [to] help clarify the interfacing role of IPBES and the ultimate impacts the Platform seeks to achieve as external contexts evolve. Essential to the mission is that the four functions of IPBES are seen and managed as an integrated set. In particular, IPBES should be more robust in recognizing that its ability to contribute to long-term, sustainable and transformative impacts through knowledge generated by assessments will largely rely on its capacities to address more prominently and successfully its other three functions' (IPBES, 2019c:8).

This is a direct challenge to how IPBES will operate in the future and a warning that a simple, incremental approach to adoption of the findings that are easier or less confrontational will not generate the magnitude of change needed. Implementation of the review in full by the next Plenary (IPBES-8) means transformative learning and reflexivity will become essential components of practice within IPBES from Plenary to authors, to those building capacities, and those working to bring other knowledge systems to the table.

\section{Discussion}

Diverse forms of learning are taking place within IPBES. However, as illustrated in the three examples above, not all of them can qualify

\footnotetext{
${ }^{5}$ Officially IPBES has four functions: to catalyse the generation of new knowledge; to produce assessments of existing knowledge; to support policy formulation and implementation; and to build capacities relevant to achieving its goal. (see www.IPBES.net).
}

unproblematically as transformative. Sections 2.1. and 2.2 on learning from experience and on the fellowship programme mention some examples of single-loop learning, oriented towards doing assessments more efficiently and navigating global negotiations. These forms of learning are more pragmatic than reflexive, the objective being to achieve an objective (such as conducting an assessment) more quickly or efficiently - but not questioning the objective itself. The review process described in section 2.3 gives some indication regarding what second-loop, arguably transformative, learning might look like. The review emphasises the need to think more about, and do more with, the policy side. Another significant innovation within IPBES is the creation of a stakeholder network that aims at engaging more directly with international civil society organisations (Díaz-Reviriego et al., 2019; Esguerra et al., 2017). Arguably, some other examples of double loop learning exist such as fixing problems in the functioning of IPBES and reaching out to marginalized forms of expertise (e.g. Larigauderie et al., 2016). In this respect, the social organisation of IPBES is distinctively different and more disciplines as well as more scales are included than in previous similar initiatives. The fact that IPBES has a mandate that comes from national delegations is particularly noteworthy. This means that IPBES has learned in different ways and in different places, but this has not really institutionalised well yet.

One example is the suggestion that IPBES should be more critical of whether assessments are the right tool for the job. As emphasised in the review, there is still a need to move beyond assessments and many people are worried of 'assessment fatigue' (Rothman et al., 2009; Turnhout et al., 2014). As we have shown, assessments are learning spaces for those who take part in them, but they are obviously chiefly intended to be learning tools providing actionable knowledge for those who read them. In the case of intergovernmental assessments, the intended audience has always been policymakers and wider civil society. As IPBES gradually moves into trying to inform practitioners alongside policymakers, it continues to rely on a model of undertaking assessments that is largely derived from the '(perceived) demand for science' (Sarewitz and Pielke, 2007) amongst many academics. These huge assessments reports are essentially treated as comprehensive literature reviews that are co-produced through various stages of peer review (comments on drafts, etc.). In Plenary, the platform members have the chance to co-produce a Summary for Policymakers, which assumes the public face of the assessment itself, and is typically used mainly by the academic community (Newman, 2017; Barkemeyer et al., 2016). This model has proliferated and has expanded to include more stakeholders, disciplines, sources of credible knowledge (e.g. think tank reports), knowledge systems, and scales. Yet, the model is still pretty much the same as it was over 30 years ago and continues to be constrained by diverse interpretations of what is 'policy-relevant' as opposed to 'policy prescriptive' (Turnhout et al., 2016). Moreover, as we pointed out, it continues to be enabled and constrained by a strongly consolidated and self-sustaining UN (eco)system. In many ways, despite 'assessment fatigue', intergovernmental assessments have become a leviathan in international science-policy settings - perpetuating a set of dependencies to sustain a life of its own.

At the same time, however, there is no denying that many changes have happened since the Global Biodiversity Assessment (1995) and the Millennium Ecosystem Assessment (2005). Moreover, learning is not a linear process and transformative learning itself cannot be easily captured. Monitoring some aspects, e.g. whether IPBES is actually achieving expert diversity in terms of discipline, regions and genderbalance (see Montana and Borie, 2016) is possible but other forms of learning, more diffuse, or taking place in shadow spaces - for example within delegations, related to informal interactions in the corridors, etc. - cannot be measured. IPBES, as any other organisations, has a 'formal' existence with some formally delineated spaces and processes. But this is only the emerged part of an iceberg of interactions that are not formally captured (see Montana, 2019). Yet, literature suggests that when it comes to contribution to learning both formal and shadow spaces are 
crucial (e.g. Pelling et al., 2008; Pallett and Chilvers, 2013). Hence, too much formalisation is not desirable either. Additionally, delineating relevant indicators to monitor learning will create a logic of its own: as with any assessment or audit process, if performance is based on a specific set of indicators then other forms of learning will be left out with unintended consequences (see Power, 1997).

In other words, the contribution of informal spaces to reflexive transformation is hard to monitor - but it is possible to recognize that these spaces are important and to encourage them (see Pallett, 2018). Ultimately, different forms of learning exist and what matters is the process leading to the decision of keeping to do things in the same way (e.g. doing assessment) or differently (e.g. doing capacity-building for policy makers). Decisions around each bifurcation ought to be made reflexively. For this reason, although 'reflexive' transformative learning is not easy to institutionalise (Pallett and Chilvers, 2013; 2015), it is important to think about mechanisms which may help formalise it so that it becomes easier for IPBES to initiate this kind of learning and contribute to individual, institutional and social transformations. Revisiting those mechanisms (of formalisation) is part of reflexive learning itself and, of course, an iterative process.

\section{Creating possibilities for transformative learning}

Different elements explaining why transformative learning is hampered have been identified. These include, for example, the difficulty to move away from a linear model of expertise that relies on a narrow understanding of expertise and scientific credibility (Beck et al., 2014; Kovács and Pataki, 2016). The intergovernmental context also comes with its own set of challenges and the use of consensus to adopt decisions between delegates also means that alternative views are not easily accounted for (see Montana, 2017). Of course, practical and financial constraints come into play too: the saying "there is no need to reinvent the wheel" is often heard during IPBES Plenaries.

In this context, different mechanisms might facilitate transformative learning. Some have been explicitly mentioned by IPBES itself, in particular the idea to adopt a rolling work plan which would allow IPBES Plenary to revisit the work programme iteratively (decision IPBES 7/1). The IPBES review is perhaps the most deliberately reflexive exercise undertaken so far, but while the review was accepted by the Plenary, uptake of the transformative learning inherent in the review by the Plenary and all subsidiary interests has yet to materialise. If it is not to be simply a production line for science assessments IPBES needs transformative learning at the heart of its objectives and activities to enable rapid and sustained uptake of its products and ideas by the international community.

A concrete idea would be for IPBES to designate a 'Reflexivity Officer', this may be an IPBES fellow or someone within the Secretariat with some time dedicated to do this. Alternatively, an informal group, for example 'Friendly enemies' or 'Critical Friends', gathering people involved in the different IPBES units could constitute a reflexivity task force. This would also help IPBES anticipate conflicts and controversies. The mission of this reflexivity officer, or task force, could be organised as follows:

(i) Initiate the development of a participatory monitoring and evaluation framework for major IPBES bodies and stakeholders. This mission may include the development of indicators to monitor progress in IPBES in terms of inclusiveness, the recommendations formulated in the review, and other aspects to be chosen in a participatory manner;

(ii) Conduct regular interviews with members of the different IPBES units to identify problems and misunderstandings early on. This does not need to be systematically time-intensive and could also include short online surveys (feedback form type) or a 'virtual suggestion box' to compile matters of concerns, observations, and other ideas;

(iii) Set up an alumni network of fellows, experts, and authors who have been involved in IPBES work (building on the idea of IPBES fellowship alumni network);

(iv) Keep track of and share the literature published on IPBES. For such a young organisation it has been extensively researched but there is currently no systematic process to compile these. Yet, the academic literature provides useful material for IPBES to reflect on how it is doing while revealing it performative effects.

These activities will be important in helping IPBES reflect on its vision, mission, successes and shortcomings.

Importantly these institutional mechanisms are not contradictory, but complementary, to the importance of experiential learning for deeper transformation. We would argue that reflexive transformations must happen within to inform reflexive transformations beyond, opening-up towards a broader range of possible futures and policy options (see Oliver and Boaz, 2019; Beck et al., 2014). This is especially important as IPBES members are exploring the possibility to conduct an assessment on 'the determinants of transformative change and options for achieving the 2050 Vision for Biodiversity' with a scoping meeting planned in $2020^{6}$. Given this assessment's ambitious scope, which reflects IPBES' aspiration to provide rationale and information leading to large-scale societal changes (see Díaz et al., 2019), there are clear opportunities for innovations and reflexivity that IPBES should not overlook. Another noteworthy effort currently underway is the 'Methodological assessment regarding the diverse conceptualization of multiple values of nature and its benefits" which is an opportunity to unpack assumptions regarding interactions between humans and nature and how value is created in different cultures and settings, potentially leading to alternative ways of valuing nature. Additionally, in an early scoping phase are methodological assessments on the interlinkages among biodiversity, water, food and health in the context of climate change and the underlying causes of biodiversity loss, determinants of transformative change and options for achieving the 2050 vision for biodiversity. These near-complete and nascent assessments offer important potential for transformative learning and reflexivity, within but also beyond IPBES. The nettle of transformative learning is ready- will the global science and policy communities be brave enough to grasp it?

\section{CRediT authorship contribution statement}

Maud Borie: Writing - original draft, Writing - review \& editing, Conceptualization. Karin M. Gustafsson: Writing - review \& editing, Conceptualization. Noam Obermeister: Writing - review \& editing, Conceptualization. Esther Turnhout: Writing - review \& editing, Conceptualization. Peter Bridgewater: Writing - review \& editing, Conceptualization.

\section{Declaration of Competing Interest}

The authors declare that they have no known competing financial interests or personal relationships that could have appeared to influence the work reported in this paper.

\section{Acknowledgements}

We thank the two anonymous reviewers for their insightful reviews which have strengthened the argument and for their suggestion regarding the 'virtual suggestion box' and 'alumni network' which we have added to the text. We are also indebted to Pallett and Chilvers (2013) for providing inspiration for the title of this paper and previous discussions on organisational learning.

\footnotetext{
${ }^{6}$ https://www.ipbes.net/event/tbc-scoping-meeting-transformative-changeassessment (last accessed November 29th, 2019).

${ }^{7}$ https://ipbes.net/values-assessment (last accessed March 4th, 2020).
} 


\section{References}

Argyris, C., Schön, D.A., 1997. Organizational learning: a theory of action perspective. Reis 77/78, 345-348.

Barkemeyer, R., Dessai, S., Monge-Sanz, B., Renzi, B.G., Napolitano, G., 2016. Linguistic analysis of IPCC summaries for policymakers and associated coverage. Nat. Clim. Change 6 (3), 311.

Beck, S., Borie, M., Chilvers, J., Esguerra, A., Heubach, K., Hulme, M., Lidskog, R., Lövbrand, E., Marquard, E., Miller, C., Nadim, T., 2014. Towards a reflexive turn in the governance of global environmental expertise. The cases of the IPCC and the IPBES. GAIA-Ecol. Perspect. Sci. Soc. 23 (2), 80-87.

Borie, M., 2016. Between Nowhere and Everywhere: The Challenges of Placing the Intergovernmental Platform on Biodiversity and Ecosystem Services (IPBES) (Doctoral dissertation, University of East Anglia).

Bridgewater, P., Rotherham, I.D., 2019. A critical perspective on the concept of biocultural diversity and its emerging role in nature and heritage conservation. People and Nature.

Bridgewater, P., Loyau, A., Schmeller, D.S., 2019. The Seventh Plenary of the Intergovernmental Platform for Biodiversity and Ecosystem Services (IPBES-7): A Global Assessment and a Reshaping of IPBES.The Seventh Plenary of the Intergovernmental Platform for Biodiversity and Ecosystem Services (IPBES-7): A Global Assessment and a Reshaping of IPBES.

IAC (Inter Academy Council), 2010. Climate Change Assessments: Review of the Processes and Procedures of the IPCC. IAC, Amsterdam.

Díaz, S., Demissew, S., Joly, C., Lonsdale, W.M., Larigauderie, A., 2015. A Rosetta Stone for nature's benefits to people. PLoS Biol. 13 (1), e1002040.

Díaz, S., Settele, J., Brondízio, E.S., Ngo, H.T., Agard, J., Arneth, A., Balvanera, P., Brauman, K.A., Butchart, S.H., Chan, K.M., Garibaldi, L.A., 2019. Pervasive humandriven decline of life on Earth points to the need for transformative change. Science 366 (6471).

Díaz-Reviriego, I., Turnhout, E., Beck, S., 2019. Participation and inclusiveness in the intergovernmental science-Policy platform on biodiversity and ecosystem services. Nat. Sustain. 1.

Dryzek, J.S., Pickering, J., 2017. Deliberation as a catalyst for reflexive environmental governance. Ecol. Econ. 131, 353-360.

Esguerra, A., Beck, S., Lidskog, R., 2017. Stakeholder engagement in the making: IPBES legitimization politics. Glob. Environ. Polit. 17 (1), 59-76.

Gieryn, T.F., 1983. Boundary-work and the demarcation of science from non-science: strains and interests in professional ideologies of scientists. Am. Sociol. Rev. 781-795.

Gustafsson, K.M., 2018. Producing expertise. The Intergovernmental Science-Policy Platform on Biodiversity \& Ecosystem Services' socialisation of young scholars. J. Integr. Environ. Sci. 15 (1), 21-39.

Gustafsson, K.M., Berg, M., Lidskog, R., Löfmarck, E., 2019. Intersectional boundary work in socializing new experts. The case of IPBES. Ecosyst. People 15 (1), 181-191.

Heink, U., Marquard, E., Heubach, K., Jax, K., Kugel, C., Nesshoever, C., Neumann, R.K., Paulsch, A., Tilch, S., Timaeus, J., Vandewalle, M., 2015. Conceptualizing credibility, relevance and legitimacy for evaluating the effectiveness of science-policy interfaces: challenges and opportunities. Sci. Public Policy 42 (5), 676-689.

Hughes, H., Vadrot, A.B., 2019. Weighting the world: IPBES and the struggle over biocultural diversity. Glob. Environ. Polit. 19 (2), 14-37.

Hulme, M., Mahony, M., Beck, S., Görg, C., Hansjürrgens, B., Hauck, J., Nesshöver, C., Paulsch, A., Vandewalle, M., Wittmer, H., Böschen, S., 2011. Science-policy interface: beyond assessments. Science 333 (6043), 697-698.

IPBES, 2012. Functions, Operating Principles and Institutional Arrangements of the Intergovernmental Platform on Biodiversity and Ecosystem Services (as Adopted in Panama, April 2012). Available at:. https://www.ipbes.net/sites/default/files/ downloads/Functions $\% 20$ operating\%20principles $\% 20$ and $\% 20$ institutional $\% 20$ arrangements $\% 20$ of $\% 20$ IPBES_2012.pdf.

IPBES, 2019a. Summary for Policymakers of the IPBES Global Assessment. Advanced Version (16 May 2019). available at:. https://www.ipbes.net/sites/default/files/ downloads/spm_unedited_advance_for_posting_htn.pdf.

IPBES, 2019b. Review of the Effectiveness of the Administrative and Scientific Functions of the Platform (5 March 2019). available at. https://www.ipbes.net/system/tdf/ ipbes-7-5_en_review.pdf? file $=1$ \& type $=$ node $\&$ id $=29737$.

IPBES, 2019c. Report on the Review of the Platform at the End of Its First Work Programme (IPBES/7/INF/18) (14 March 2019), 99pp. Available at:. . https:// www.ipbes.net/system/tdf/ipbes-7-inf-18_review.pdf?file =1\&type = node\&id = WWW.1P.

Jasanoff, S., 1987. Contested boundaries in policy-relevant science. Soc. Stud. Sci. 17 (2), 195-230.

Jasanoff, S., 2007. Technologies of humility. Nature 450 (7166), 33.

Kolb, D.A., 2014. Experiential Learning: Experience as the Source of learning and Development. FT press.

Kolb, A.Y., Kolb, D.A., 2005. Learning styles and learning spaces: enhancing experiential learning in higher education. Acad. Manag. Learn. Educ. 4 (2), 193-212.

König, A., 2015. Changing requisites to universities in the 21st century: organizing for transformative sustainability science for systemic change. Curr. Opin. Environ. Sustain. 16, 105-111.

Kovács, E.K., Pataki, G., 2016. The participation of experts and knowledges in the Intergovernmental Platform on Biodiversity and Ecosystem Services (IPBES). Environ. Sci. Policy 57, 131-139.

Larigauderie, A., Stenseke, M., Watson, R.T., 2016. Biodiversity assessments: IPBES reaches out to social scientists. Nature 532 (7599), 313.
Leemans, R., 2008. Personal experiences with the governance of the policy-relevant IPCC and Millennium Ecosystem Assessments. Global Environ. Change 18 (1), 12-17.

Marton, F., Säljö, R., 1976. On qualitative differences in learning: I-outcome and process. Br. J. Educ. Psychol. 46 (1), 4-11.

Mezirow, J., 1978. Education for Perspective Transformation: Women's Re-Entry Programs in Community Colleges. Teacher's College, Columbia University, New York.

Mezirow, J., 1997. Transformative learning: theory to practice. New Dir. Adult Contin. Educ. 1997 (74), 5-12.

Montana, J., 2017. Accommodating consensus and diversity in environmental knowledge production: achieving closure through typologies in IPBES. Environ. Sci. Policy 68, 20-27.

Montana, J., 2019. Co-production in action: perceiving power in the organisational dimensions of a global biodiversity expert process. Sustainability Sci. 14 (6), 1581-1591.

Montana, J., Borie, M., 2016. IPBES and biodiversity expertise: regional, gender, and disciplinary balance in the composition of the interim and 2015 multidisciplinary expert panel. Conserv. Lett. 9 (2), 138-142.

Newman, T.P., 2017. Tracking the release of IPCC AR5 on twitter: users, comments, and sources following the release of the working group I summary for policymakers. Public Underst. Sci. 26 (7), 815-825.

O'Brien, K., 2012. Global environmental change II: from adaptation to deliberate transformation. Prog. Hum. Geogr. 36 (5), 667-676.

Obermeister, N., 2017. From dichotomy to duality: addressing interdisciplinary epistemological barriers to inclusive knowledge governance in global environmental assessments. Environ. Sci. Policy 68, 80-86.

Obermeister, N., 2019. Local knowledge, global ambitions: IPBES and the advent of multiscale models and scenarios. Sustain. Sci. 14 (3), 843-856.

Oliver, K., Boaz, A., 2019. Transforming evidence for policy and practice: creating space for new conversations. Palgrave Commun. 5 (1), 1.

Pallett, H., 2018. Situating organisational learning and public participation: stories, spaces and connections. Trans. Inst. Br. Geogr. 43 (2), 215-229.

Pallett, H., Chilvers, J., 2013. A decade of learning about publics, participation, and climate change: institutionalising reflexivity? Environ. Plan. A 45 (5), 1162-1183.

Pallett, H., Chilvers, J., 2015. Organizations in the making: learning and intervening at the science-policy interface. Prog. Hum. Geogr. 39 (2), 146-166.

Pelling, M., High, C., Dearing, J., Smith, D., 2008. Shadow spaces for social learning: a relational understanding of adaptive capacity to climate change within organisations. Environ. Plan. A 40 (4), 867-884.

Power, M., 1997. The Audit Society: Rituals of Verification. OUP Oxford.

Reber, A.S., 1989. Implicit learning and tacit knowledge. J. Exp. Psychol. Gen. 118 (3), 219.

Rothman, D.S., van Bers, C., Bakkes, J., Pahl-Wostl, C., 2009. How to make global assessments more effective: lessons from the assessment community. Curr. Opin. Environ. Sustain. 1 (2), 214-218.

Sarewitz, D., Pielke Jr, R.A., 2007. The neglected heart of science policy: reconciling supply of and demand for science. Environ. Sci. Policy 10 (1), 5-16.

Scoones, I., Newell, P., Leach, M., 2015. The politics of green transformations. The politics of green transformations (pp. 19-42). Routledge.

Scoones, I., Stirling, A., Abrol, D., Atela, J., Charli-Joseph, L., Eakin, H., Ely, A., Olsson, P., Pereira, L., Priya, R., van Zwanenberg, P., 2020. Transformations to sustainability: combining structural, systemic and enabling approaches. Curr. Opin. Environ. Sustain. 42, 65-75.

Smith, A., Stirling, A., 2007. Moving outside or inside? Objectification and reflexivity in the governance of socio-technical systems. J. Environ. Policy Plann. 9 (3-4), 351-373.

Smith, A., Stirling, A., Berkhout, F., 2005. The governance of sustainable socio-technical transitions. Res. Policy 34 (10), 1491-1510.

Stevance, A.S., Bridgewater, P., Louafi, S., King, N., Beard Jr, T.D., Van Jaarsveld, A.S., Ofir, Z., Kohsaka, R., Jenderedijan, K., Rosales Benites, M., Mulongoy, K.J., 2020. The 2019 review of IPBES and future priorities: reaching beyond assessment to enhance policy impact. Ecosystems and People 16 (1), 70-77.

Taylor, E.W., Cranton, P., 2012. The Handbook of Transformative Learning: Theory, Research, and Practice. John Wiley \& Sons.

Tengö, M., Hill, R., Malmer, P., Raymond, C.M., Spierenburg, M., Danielsen, F., Elmqvist, T., Folke, C., 2017. Weaving knowledge systems in IPBES, CBD and beyond-lessons learned for sustainability. Curr. Opin. Environ. Sustain. 26, 17-25.

Turnhout, E., Bloomfield, B., Hulme, M., Vogel, J., Wynne, B., 2012. Conservation policy: listen to the voices of experience. Nature 488 (7412), 454.

Turnhout, E., Neves, K., De Lijster, E., 2014. Measurementality'in biodiversity governance: knowledge, transparency, and the Intergovernmental Science-Policy Platform on Biodiversity and Ecosystem Services (IPBES). Environ. Plan. A 46 (3), 581-597.

Turnhout, E., Dewulf, A., Hulme, M., 2016. What does policy-relevant global environmental knowledge do? The cases of climate and biodiversity. Curr. Opin. Environ. Sustain. 18, 65-72.

Visconti, P., Butchart, S.H., Brooks, T.M., Langhammer, P.F., Marnewick, D., Vergara, S., Yanosky, A., Watson, J.E., 2019. Protected area targets post-2020. Science 364 (6437), 239-241.

Voss, J.P., Bauknecht, D., Kemp, R., 2006. Reflexive Governance for Sustainable Development. eds.. Edward Elgar Publishing.

Westley, F., Olsson, P., Folke, C., Homer-Dixon, T., Vredenburg, H., Loorbach, D., Thompson, J., Nilsson, M., Lambin, E., Sendzimir, J., Banerjee, B., 2011. Tipping toward sustainability: emerging pathways of transformation. Ambio 40 (7), 762. 